\title{
Influence of CMM Scanning Speed and Inspected Feature Size on an Accuracy of Size and Form Measurement
}

\author{
Jan Urban ${ }^{1}$, Libor Beranek ${ }^{1}$, Michal Koptiš ${ }^{1}$, Jan Šimota ${ }^{1}$, Ondřej Košt’ák ${ }^{2}$ \\ ${ }^{1}$ Faculty of Mechanical Engineering, Czech Technical University in Prague. Technicka 4, 16000 Prague 6. Czech \\ Republic. E-mail: Jan.Urban@fs.cvut.cz, Libor.Beranek@fs.cvut.cz, Michal.Koptis@fs.cvut.cz, \\ Jan.Simota@fs.cvut.cz \\ ${ }^{2}$ Skoda Auto a.s., Trida Vaclava Klementa 869, 29301 Mlada Boleslav, Czech Republic. E-mail: On- \\ drej.Kostak@skoda-auto.cz
}

Modern production systems requires high effectivity and flexibility with always increasing demands for precision as an imperative for more efficient components. The same apply for quality inspection providing data for feedback regulation of production processes. CMMs (coordinate measuring machines) which are flexible and universal in use yet very accurate and easy to automate are a standard mean for quality inspection. With many sensors available on the market, central fixed scanning heads with tactile scanning probes are a reference equipment for inspection of precise production of engine and transmission components. Tactile probes are right choice where very high accuracies and stability of results is required. Effectivity was allways a target in production processes and today the same pressure for effectivity and productivity is required from measuring machines, yet measurement strategies are often taken from measurement plans even 10 years old. This means that in old programs low scan speeds are used based on capability of older technologies and the approach of don't change it when it works is common. This limits productivity of the whole quality control process. Motivation for this paper and whole research is to increase productivity and thus capacity of quliaty inspection without compromising process capability. Lack of measuring capacity is usually solved by purchase of a new machine which may not be allways necessary. Primary motivation of companies supplying these technologies is not maximum efficiency of quality inspection, which in context of spare capacities ultimately means lower sales. Aim of this article is to describe influence of scanning speed and size of inspected feature on CMMs accuracy. High-precision CMM control itself is not easy because with decreasing path radius dynamic effects of machine construction itself increase on measurement results. Accuracy of CMM measurement is then function of feature size being checked. This knowledge can be used for optimization of measurement plans in terms of productivity while maintaining sufficient measurement accuracy depending on required tolerance.

Keywords: CMM, Productivity of measurement, Scanning speed, capability of measurement

\section{Introduction}

As a result of fundamental development from recent years it is no problem to produce very complicated parts with high precision where we need tolerance in hundredths of millimetre. Highly specialized machines are then able to produce even below this limit. However, we must be able to control/measure this accurate production productively and correctly. CMMs are appropriate choice for this purpose and in recent years they have been used a lot. Main reason for their deployment is to exclude human factor from dimensional quality control process which is significant source of measurement variability. Other reasons for using CMM are versatility, accuracy and productivity. Machine will rapidly increase productivity compared to conventional devices (like callipers, etc.) but input costs of this machine are in thousands euros. Of course, correct implementation is important. This is investigated via coefficients cg and cgk (gauge capability) which describes level of accuracy and precision of measuring system. Standardly actual measurement programs are designed to fulfil coefficients values, however time required for measurement is for some companies marginally. From previously published experiments is known that scanning speed affects productivity and measurement capability. In practice, values of these coefficients exceeding even more than ten times necessary limit of gage capability (1.33). This situation then provides potential to increase speed and thus reduce time required for measurement. Modern times require high demands on productivity in production and productivity of CMMs must correspond accordingly. In some publications is describe influence of stylus system configuration on variability of measurement result [1], description of dynamic effects CMM machine on sensor system [2], or first indications 
about scanning speed effect for straightness measurements [3]. However, most of measured elements are circular on engineering products. In overall context, there are currently no systematic efforts to make CMM measurement process more productive. Motivation for this article was also long-term cooperation with Škoda Auto a.s., where pressure on maximum possible useable of available measurement capacities is high. At beginning of this cooperation was study which describe theoretical potential to increase capacity of dimensional quality control about $10 \%$ by simply reprogram measurement strategy on CMMs while maintaining capability.

\section{Measurement strategy}

Actual most common measuring systems mounted on CMMs are tactile systems. Across industrial applications, they can be found in versions with fixed or rotating heads (mean mounted on stationary CMMs). Thanks to their flexibility a rotating heads are used for measuring components with complex shapes (freeforms) where a lot tactile styluses would be required. Fixed systems are used in cases where high accuracy is required and this publication is focused on parts with high requirements. The industry habit for controlling precision manufacturing applications is uses fixed systems. Measurement strategy using scanning systems represents scan setting parameters such as path type (which points are extracted from part surface), scanning speed, distance between each point (number of points), parameters for filtering measured points, eliminating outliers and method of numerical calculating geometrical elements. Strategy as a complex is defined by machine operator and is absolutely important from point of ensuring measurement accuracy. Some parameters affect measurement productivity. Mainly length of scanned path and scanning speed. Scan path length adjustment leads to reduce number of points on individual elements and thus also to reduce information about elements as a whole. For this reason article focuses attention to scanning speed because it has major impact on productivity of measurement while whole information remains unchanged. Other ways to increase measurement productivity can be optimize measurement configuration, for example optimize safety positions, non-measurement paths around part. Accelerate stylus system configuration replacement and reduce computing times with more powerful computer equipment. However, these methods do not affect the value of the measurement process capability and therefore they will not be in our interest.

\section{Gage capability $C_{g}$ and $C_{g k}$}

Whole dimensional inspection process needs to be evaluated in some way to see if it is suitable for specific application. For this reason gage capability coefficients $c_{g}$ and $c_{g k}$ have been introduced. It is mathematicalstatistical tool (type 1 gage study from MSA) assesses effects of bias and repeatability on measurements from one operator and one reference part. Coefficient $\mathrm{c}_{\mathrm{g}}$ describes ratio between precision and tolerance (potential capability) while $c_{\mathrm{gk}}$ describes ratio between accuracy and tolerance (actual capability). Precision (repeatability) is expressed as a standard deviation found by simply taking standard deviation of all repeated measurements. Calculation is then performed according to relations (formula 1 and formula 2). Process is capable if both coefficients are greater than 1.33.

$$
\begin{gathered}
c_{g}=\frac{0.2 * T}{6 * S_{g}} \\
c_{g k}=\frac{0.1 * T-\left|\bar{x}_{g}-\bar{x}_{m}\right|}{3 * S_{g}}
\end{gathered}
$$

Where:

T...process tolerance $[\mathrm{mm}]$

$\mathrm{S}_{\mathrm{g}}$...standard deviation of measurements (precision) [mm]

$\bar{x}_{g} \ldots$ mean of all measurements $[\mathrm{mm}]$

$\bar{x}_{m} \ldots$...reference value $[\mathrm{mm}]$

\section{Feasibility study}

In cooperation with Škoda Auto a.s. and based on above findings a feasibility study of intent to optimize CMM measurement program was conducted and main focus was only in scanning speed changes. Optimization was carried out on CMM Zeiss UMC 850 Carat which has quality control department for production of aggregate components. It's machine with active Vast Gold scanning system and specifications according to VDI / VDE $2617 \mathrm{u} 3=1.8+\mathrm{L} / 450$ $\mu \mathrm{m}$. Measurement program was optimized for dimensional inspection of cylinder heads 1.0 MPI engine after manufacturing operations 10 and 20. This part shows Figure 1. Optimization process was divided into several steps. First step was analyse strategy settings of both programs. Subsequently ten repetitions measurement of same part was measured for provide information about accuracy and precision of all controlled characteristics. These properties represent the coefficients $c_{g}$ and $c_{g k}$ as described above. In order to determine reference values required for $\mathrm{c}_{\mathrm{gk}}$ coefficient calculation, measurement of same part was performed on ZEISS UPMC 850 calibration machine which has specification $0.7+\mathrm{L} / 600 \mu \mathrm{m}$. Measurement on this machine was five times repeated and arithmetic mean of results was used as a reference value. Measurement plan optimization was performed only for geometrical elements whose value of coefficients $\mathrm{Cg}$ and Cgk exceeded value 5 . Adjustment affected only scan speed parameters. Values of optimized speeds was chosen only on operator's experience because this is untested methodology of program optimization. Results of re- 
peated measurements confirmed original assumptions. On average optimized programs saved 10\% time in measurement process. This was impetus for further experiments that would extent which measurement results were affected by this intervention. [4]

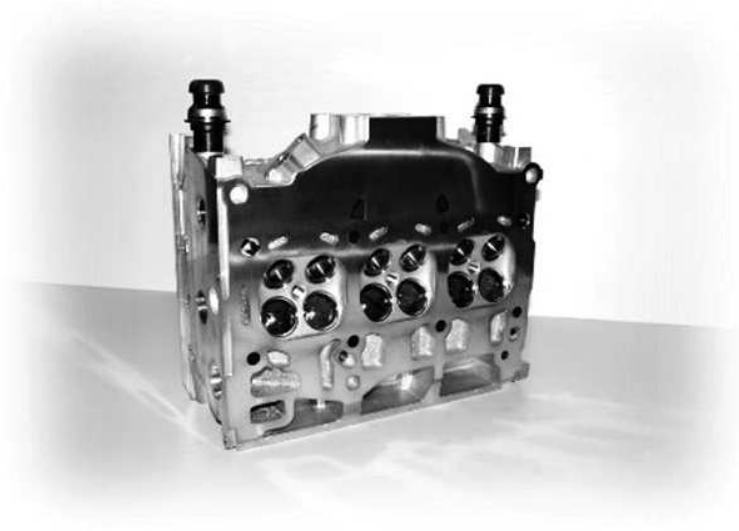

Fig. 1Cylinder head EA 211 1.0 MPi

\section{Experiment description and realization}

The study showed that it is necessary to describe effect of scanning system on overall measurement results using higher scanning speeds. On this basis, full factorial experiment was designed to define maximum usable scanning speed ensuring capability of measurements depending on circular path diameter. Two parameters were chosen as variables. First parameter is diameter (factor A), this parameter was ensure by using adjusting rings with range from $5 \mathrm{~mm}$ to $100 \mathrm{~mm}$. Step between individual diameters was $5 \mathrm{~mm}$. Second parameter was scanning speed (factor B) which corresponded to range $2-40 \mathrm{~mm} / \mathrm{s}$ with $2 \mathrm{~mm} / \mathrm{s}$ step. Each of these two factors contained 20 levels and each combination of these factors had 10 replications. Response quantities were average deviatin from reference size and roundness. Experiment was performed at Škoda Auto a.s. on Zeiss Prismo machine. This machine is equipped with active Vast Gold scanning system and is located in climate controlled metrology centre with passive damping of ambient vibrations. Laboratory temperature was $21.2^{\circ} \mathrm{C}$ at the time of experiment and maximum deviation was $\pm 0.15^{\circ} \mathrm{C}$, temperature compensation was used on measurement results with CTE $11.5^{*} 10^{-6} \mathrm{~K}^{-1}$ for a steel calibration rings. Sensor with $1.5 \mathrm{~mm}$ sphere diameter and $20 \mathrm{~mm}$ shaft length was used for scanning. Entire configuration was assembled from clamping plate for VAST head and lightweight steel extension (80x11 mm). Configuration of a sensor was designed for real measurement conditions. Results from individual rings calibration were used for $\mathrm{c}_{\mathrm{gk}}$ coefficient calculation as a reference value. Tolerances used to evaluate capability of process were on the level of $\pm 0.01 \mathrm{~mm}$ for size and $0.02 \mathrm{~mm}$ for roundness in both cases the width of tolerance was $0.02 \mathrm{~mm}$. Calibration was performed on Zeiss UPMC 850 reference machine and Hommel calibration rings gauge. [5]

\section{Experiment evaluation}

Evaluation of experiment revealed that scanning speed value used in combination with different radius of measured circular path quite fundamentally affects accuracy and precision of measurement. We will demonstrate this effect on 4 diameter values which occur at engine components production and at same time represent whole dimensions range of experiment. Selected values were: $5 \mathrm{~mm}$ diameter corresponding to mounting pins diameter, $20 \mathrm{~mm}$ diameter corresponding to valve seat on cylinder head dimension, $50 \mathrm{~mm}$ diameter corresponding to crankshaft dimension and $75 \mathrm{~mm}$ diameter corresponding to internal combustion engine block dimension. Graph in Figure 2 shows deviations obtained by subtracting reference value from arithmetic value of ten measurements for each scan speed level.

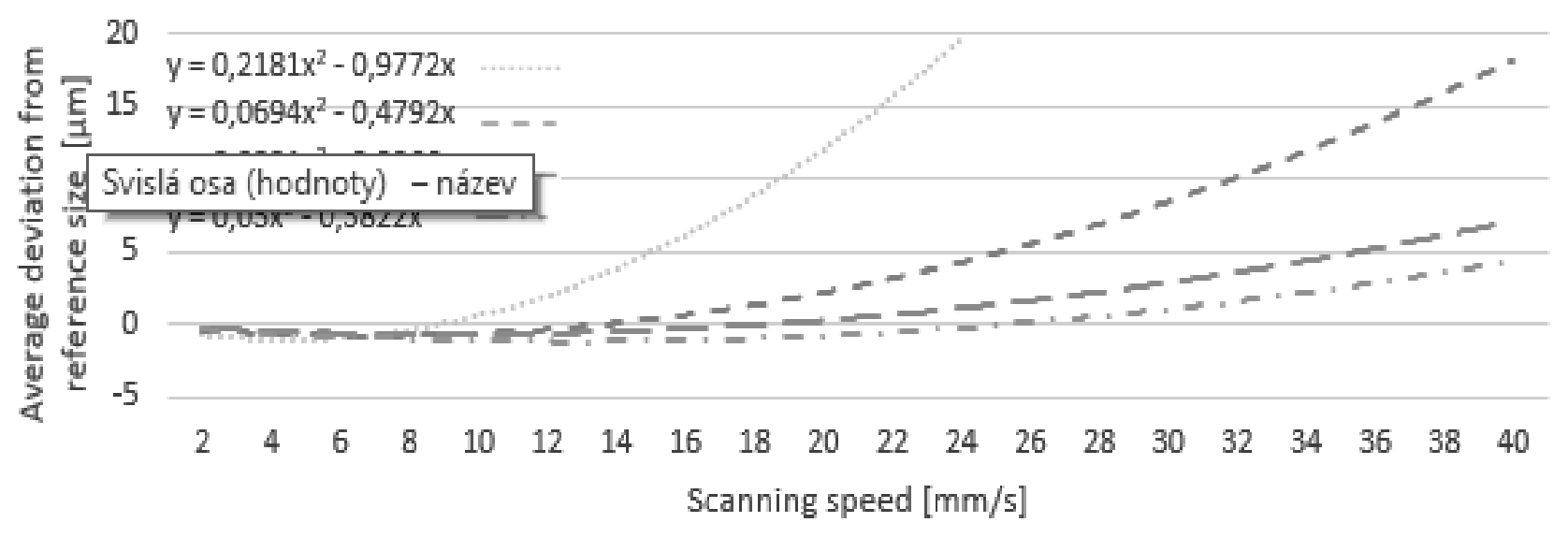

D $5 \mathrm{~mm} \quad---D 20 \mathrm{~mm} \quad-\quad-D 50 \mathrm{~mm} \quad \cdots$ D $75 \mathrm{~mm}$

Fig. 2 Influence of scanning speed on diameter deviation from reference value 
Here we can see increasing deviation of individual rings in direct connection with increasing scanning speed. This increase is more pronounced for smaller diameters. As diameter increases, this effect gradually changes. The roundness deviations are calculated in same process. The deviations are shown in Figure 3. Same trend is confirmed here as well. We can also notice that up to $6 \mathrm{~mm} / \mathrm{min}$ speed the deviations are approximately same in both cases. Above this speed, increasing difference in deviations from reference value can then be observed. This is due to different scanned path radius. With larger measured path radius the machine control reacts more smoothly due to normal vector direction changes. Normal vector defines scan points direction and thus also pressing force in individual axes. For larger diameters is smoother change of pressing force direction than smaller diameters. With increasing scan speed is more difficult to control movement of machine. Another influence that will be reflected in process is movement inertia of CMM construction, which increases with increasing speed.

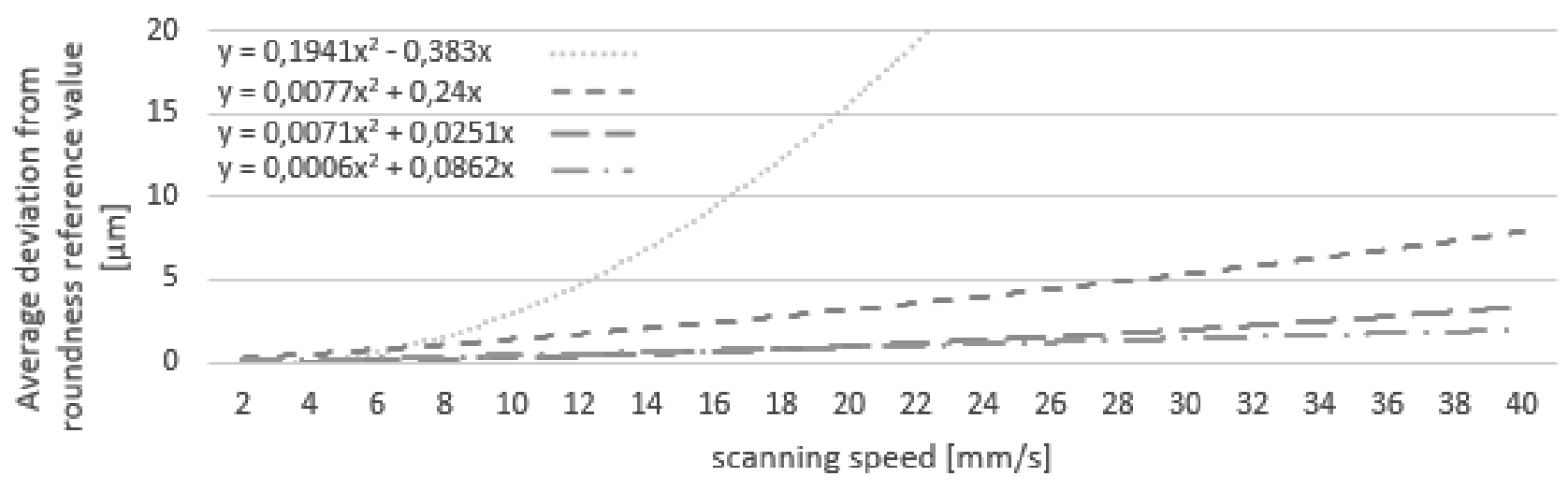

$$
\text { D } 5 \mathrm{~mm} \quad---\mathrm{D} 20 \mathrm{~mm} \quad-\text {-D } 50 \mathrm{~mm} \quad-\text { - D } 75 \mathrm{~mm}
$$

Fig. 3 Influence of scanning speed on form deviation from reference value
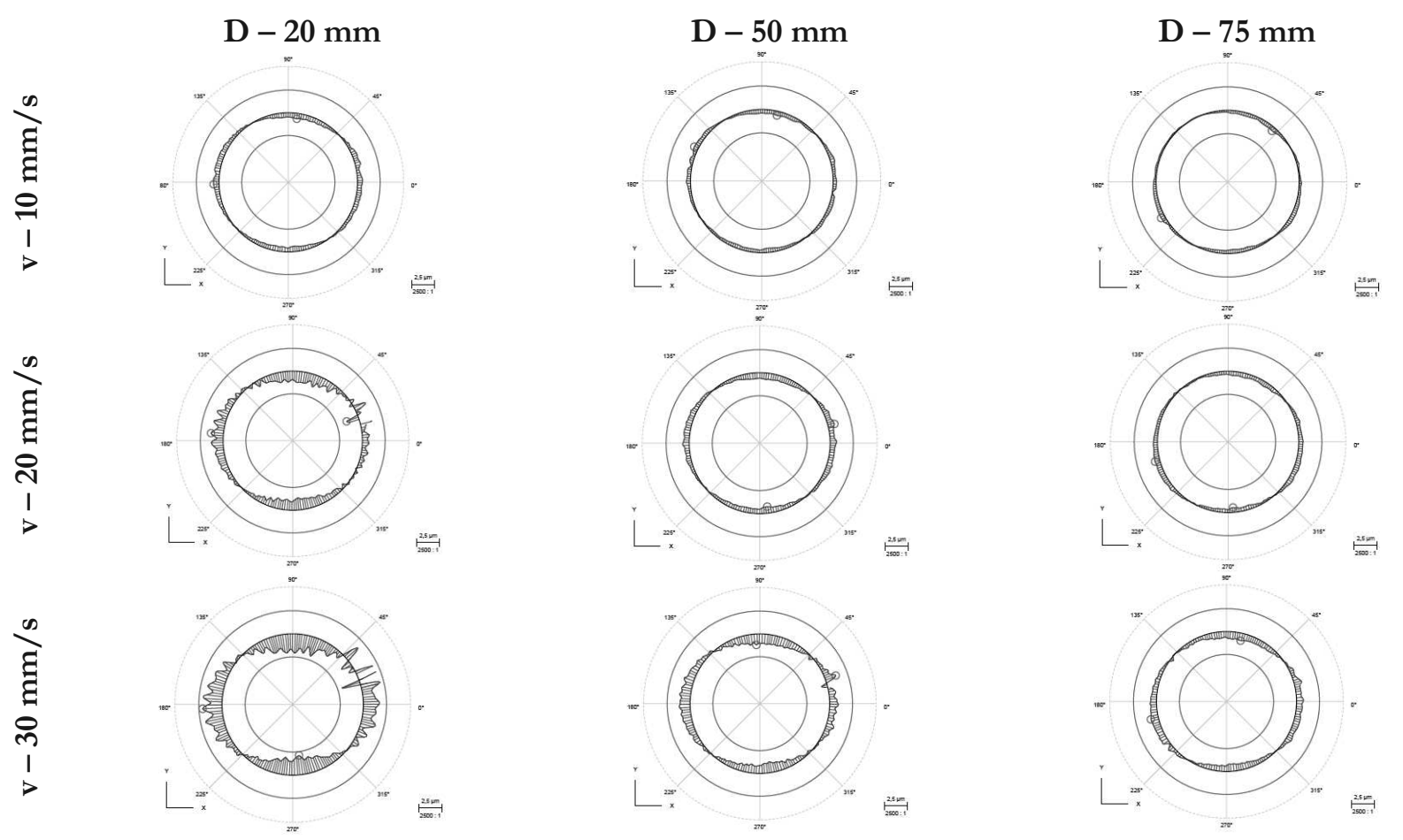

Fig. 4 Measured data graphical report for specified speeds and diameters of adjusting rings

Evaluation of roundness is displayed in Figure 4. On this figure we can see scanning path deformation with increasing scanning speed $(10,20$ and $30 \mathrm{~mm} / \mathrm{s})$ and also dependence on path diameter $(20,50$ and 75 $\mathrm{mm})$. Comparison clearly presents how important is correct measurement strategy setting for accurate results and how dynamics of machine influence measurement result. This is illustrated by step changes 
around circumference. Then we can see in Figure 4 changes of measured points in $\mathrm{X}$ and $\mathrm{Y}$ axes. These are axes where (in case of CMM with moving bridge) inertia of CMM construction is most pronounced.

Results of measured dimensions also confirm calculated values of gage capability $\mathrm{Cg}$ and Cgk for diameter evaluation. It can be seen in Figure 5. For better illustration, the values of the coefficients $\mathrm{Cg}$ and $\mathrm{Cgk}$ were approximated by a polynomial of the fourth degree. Cg coefficient is satisfactory for all selected path scanning speeds. Reason is that coefficient evaluates precision of measurement. Cg refers to ratio between precision and tolerance. Due to fact that this is measurement without human factor influence, repeatability
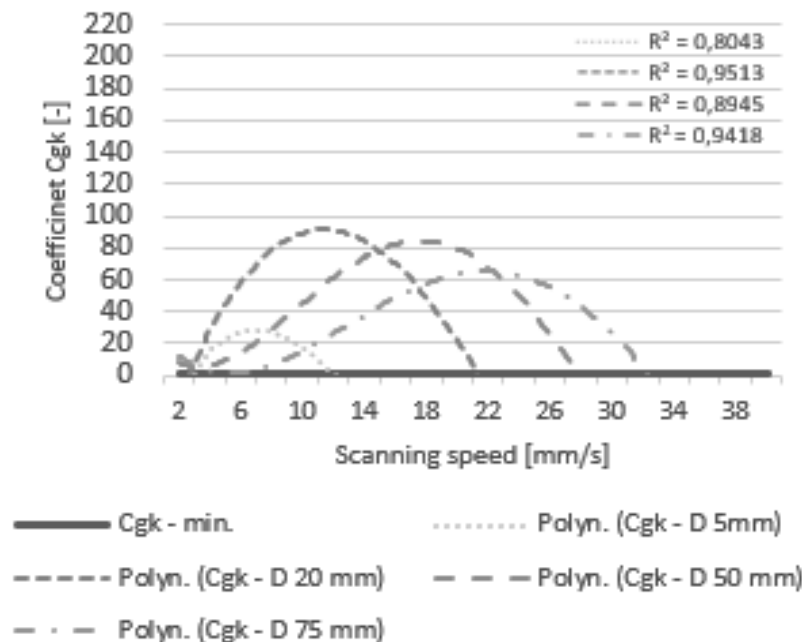

Fig. 5 Comparison of calculated capability of coefficients $C_{g}$ and $C g$ is still good. Conversely, situation is different for coefficient $\mathrm{Cgk}$ which evaluates accuracy of the measurement. Here it can be observed that individual diameters have different limit of scanning speeds when measurement process is still capable. This indicates maximum scan speeds for particular measured diameter. An interesting difference is between maximum speed for $20 \mathrm{~mm}$ diameter which can be measured correctly and accurately at speeds up to $20 \mathrm{~mm} / \mathrm{s}$ and $75 \mathrm{~mm}$ diameter where scanning speed can be used up to $32 \mathrm{~mm} / \mathrm{s}$. So it is confirmation about effect of combination scanning speed and diameter of measured element.

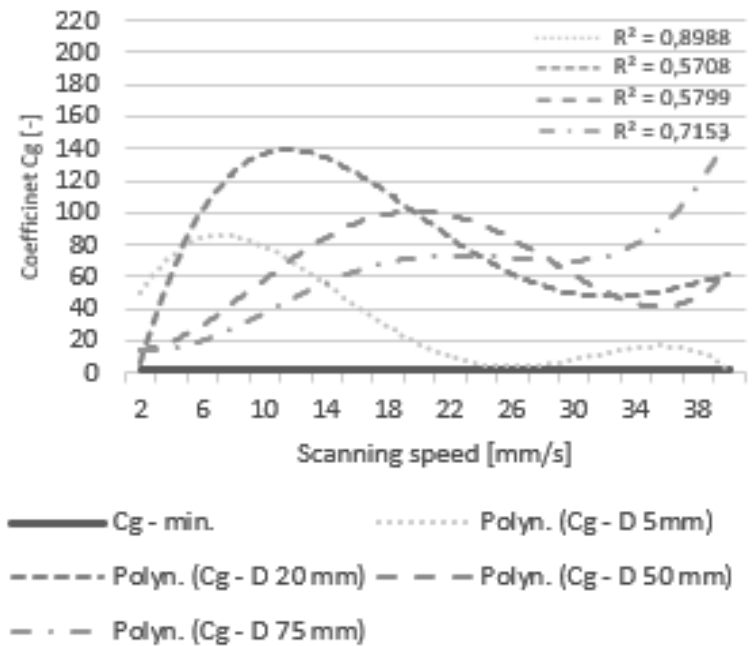

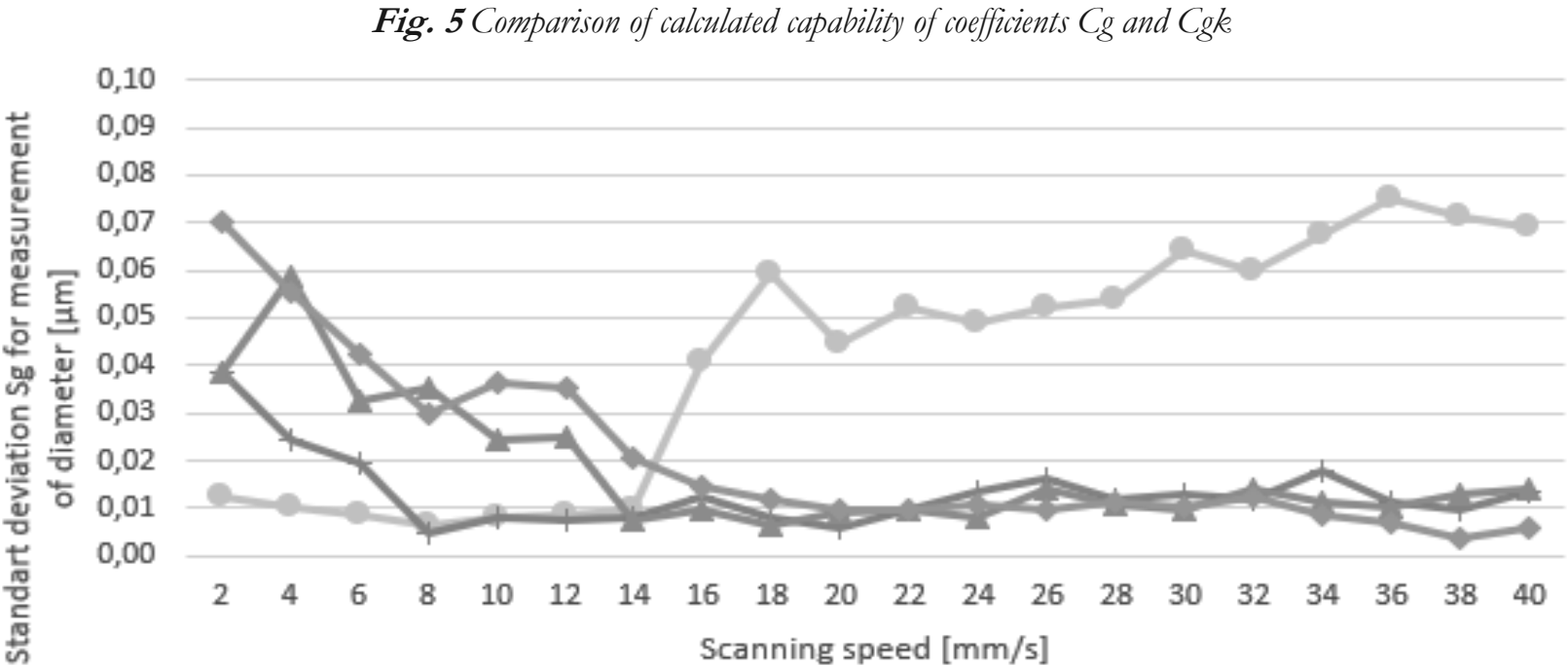

-D $5 \mathrm{~mm} \longrightarrow$ - $20 \mathrm{~mm}$-D $50 \mathrm{~mm} 75 \mathrm{~mm}$

Fig. 6 Calculated standard deviation Sg for each evaluated calibration ring: on left - measurement of diameter on right measurement of roundness

Figure 5 also shows large differences in coefficients $\mathrm{Cg}$ and Cgk calculated for different scan speed levels. This is due to dependence on standard deviation $\mathrm{Sg}$ which is used for calculation. In Figure 6 we can see standard deviation values for each scan speed level when measuring $20 \mathrm{~mm}$ diameter ring. It was not possible to involve standart deviations from 10 replications for each measurement in figures 2 and 3 because of their size, compared to measured values error bars were not visible. Standart Differences between them are very small but they still have significant effect on value of calculated coefficients. This proves how 
strict a capability coefficient evaluate measurement process.

It should also be noted that surface of adjusting ring is lapped and is almost ideal for scanning on CMM with active scanning system. Therefore, it is advisable to take scan speed setting limits as maximum. In real application, surface quality will be worse and therefore it is necessary to determine safety coefficient which will guarantee applicability of this methodology even on qualitatively worse surface. Here we would lean towards correction factor 0.66 which corresponds to $2 / 3$ of maximum speed and should safely ensure applicability of this knowledge to optimize measurement plans. Although introduction of this factor will reduce potential benefit of optimized programs but it still increases productivity.

\section{Conclusion}

The experiment clearly demonstrated a combination of the effect of the diameter of the measured circular path and the scanning speed on the measurement result accuracy. The graphs in Figures 2 and 3 show the calculated deviations from the average of the ten measurements for each scanning speed level. The increase in these deviations when using increasing speeds varies according to the measured diameter. The effect is noticeable both when evaluating the diameter and roundness and is caused by the controller and dynamical influences of the machine. When measuring smaller diameters, it is increasingly difficult to control the whole measuring machine with increasing speed. The reason is the rapidly changing values of the axial components of the normal vector, which is crucial for the control of the sensor pressure. For small diameters, the change is more pronounced with increasing speed than for larger diameters. Therefore, the control of the machine at higher speeds does not manage to regulate the components of the measuring force in the individual axes. In addition, the dynamic effects of CMM machine design are affecting measured data, which is clearly shown in Figure 4. The problem of the influence of sensor head control at higher scanning speeds of smaller diameters in combination with dynamic effects of machine design is clearly demonstrated. The direct influence of the diameter of the measured path on the recording of the measured points is evident.

Furthermore, it can be seen in graphs 2 and 3 that at lower speeds the calculated deviation of the average value from the reference dimension is negative and only from a certain scanning speed does the deviation reach positive values. This may be due to the machine used, on which serial measurement of the manufactured parts is normally carried out in continuous operation, and the machine may already show a certain de- viation from calibration still on acceptable level for serial measurement. Since all calibration rings were measured on the same machine and negative values at low speeds occurred in all measured rings compared to their calibrated values, this is probably some systematic cause, which can be caused by a worse condition of the aerostatic bearing surface in one of the machine drives. The trend was subsequently confirmed by the calculations of the coefficients $\mathrm{Cg}$ and Cgk, where at lower scanning speeds higher standard deviations of repeated measurements were calculated and subsequently also lower values of the coefficients of the capability of gauge. However, it should be emphasized that, despite the lower values of capability, the coefficients were still above 1.33 and the measurement was therefore eligible for selected tolerance width of $0.02 \mathrm{~mm}$.

The Figure 5 show the values of the coefficients $\mathrm{Cg}$ evaluating the precision and Cgk evaluating the precision and accuracy of the measurement together, which we generally refer to as the measurement accuracy. In particular, it can be seen from the values of the coefficient $\mathrm{Cgk}$ that they are quite high for certain values of scanning speed (normally exceeding 20 $\mathrm{mm} / \mathrm{s}$ ). This is due to a very small standard deviation, which is in the order of hundreds of $\mu \mathrm{m}$ and for selected diameters it's displayed in Figure 6. After exceeding a certain speed limit, however, there is a fairly steep drop below the limit capability value of 1.33 . The speed at which the capability value falls below the limit of 1.33 can then be referred to as the limit scanning speed of a specific diameter, where sufficient accuracy of the measurement represented by the coefficient Cgk is ensured. Any knowledge of these speed limits is important from the point of view of productive use of the CMM machine. This is because it provides the potential to increase the scanning speed of commonly compiled measurement plans in order to increase the productivity of dimensional inspection. As the scanning speed increases or measured diameter decreases, the trueness of measurement, represented by the average deviation from roundness reference value and average deviation from reference size, decreases as well. Unfortunately, precision described by standard deviation is increasing as displayed in Figure 6, this is common for CMM machines yet very unintuitive and thus for accuracy evaluation precision is the least relevant and trueness has to be considered.

If we keep the capability values above the limit of 1.33 with some slight safe margin for example use as a limit value of 3 , we have a room for productivity optimization and still have some safe space for potential errors. However, it should be noted that the level of the coefficients $\mathrm{Cg}$ and $\mathrm{Cgk}$ depends on the width of the tolerance field. If the width of the tolerance field is larger than $0.02 \mathrm{~mm}$ used in this study, the potential for optimization will be even more significant. 


\section{Acknowledgement}

At this point, we would like to thank Škoda Auto a.s. which provided technological equipment for experiments and helped to create this contribution.

\section{References}

[1] MIKEŠ, P. (2016). Influence of stylus system configuration on the variability of measurement result on CMM. Manufacturing Technology Journal. 2016, (Volume 16), 184 - 188. ISSN 12132489.

[2] KUMAR, A. S., C. CHANDRASEKARAN. (2019). Analysis of Dynamic Probing Errors in Measuring Machines. Innovative Design, Analysis and Development Practices in Aerospace and Automotive Engineering (I-DAD 2018). Singapore: Springer Singapore, 2019, 2019-12-15, 473-482. Lecture Notes in Mechanical Engineering. DOI: 10.1007/978-981-13-2697-4_51. ISBN 978-981-13-2696-7. Dostupné také z: http://link.springer.com/10.1007/978-98113-2697-4_51

[3] STĘPIEŃ, K. (2015). An analysis of influence of sampling strategy and scanning speed on estimation of straightness and flatness deviations with CMMs. Advanced Technologies in Mechanics. 2015, 2(2(3), 2-8. DOI: 10.17814/atim.2015.2(3).17. ISSN 2392-0327. Dostupné také z: http://atim.media.pl/index.php/ATiM/article/view/17

[4] Statistické metody ř́zení kvality. 1. Praha: Česká společnost pro jakost, 2007.

[5] URBAN, J., DVOŘÁK, R., BERÁNEK, L., ŠIMOTA, J., MIKEŠ, P., TILLINGER, K. (2017). Optimierung der Qualitätskontrolle bei Koordinatenmessgeräten binsichtlich der Messproduktivität: Studentská tviruč cinnost 2017. V Praze: Fakulta strojní ČVUT, 2017, 2017. ISBN 978-80-0106143-5.

[6] MELICHAR, M., KUBATOVA, D., KUTLWASER, J. (2017). Influence of CMM Velocity on Scanning Precision. Proceedings of the 28th International DAAAM Symposium 2017.
DAAAM International Vienna, 2017, 2017, 0400-0409. DAAAM Proceedings. DOI: 10.2507/28th.daaam.proceedings.056. ISBN 9783902734112. Dostupné také z: http://www.daaam.info/Downloads/Pdfs/proceedings/proceedings_2017/056.pdf

[7] PEREIRA, P.H. a R.J. HOCKEN. (2007). Characterization and compensation of dynamic errors of a scanning coordinate measuring machine. Precision Engineering. 2007, 31(1), 22-32. DOI: $\quad 10.1016 / \mathrm{j}$.precisioneng.2006.01.006. ISSN 01416359. Dostupné také z: https://linkinghub.elsevier.com/retrieve/pii/S014163590600047X

[8] GUNIŠ, Z., VAGOVSKÝ, J., GÖRÖG, A. (2013). Effect of Scanning Speed on the Accuracy of Measu-Red Values using Coordinate Measuring Machine. Technological Engineering. 2013,10(2), 2-5. DOI: 10.2478/teen-20130011. ISSN 1336-5967. Dostupné také z: https://content.sciendo.com/doi/10.2478/teen-20130011

[9] FACTORS AFFECTING MEASUREMENT UNCERTAINTY IN INDUSTRIAL CMM WORK. Statistica Applicata - Italian Journal of Applied Statistics. 2008, 3(22), 341-352. Dostupné také z: https://pdfs.semanticscholar.org/7318/2b950ba0df37075f11bcc39e1760 640fa2b5.pdf

[10] DIAN, M., HODINÁŘ, L. (2018). The GRR a Fundamental Tool for Dealing with Measurement System Variability. Manufacturing Techno$\log y$. 2018, 18(1), 29-34. ISSN 12132489. Dostupné z: doi:10.21062/ujep/48.2018/a/12132489/MT/18/1/29

[11] VIT, J., NOVAK, M. (2018).. A Roundness Machine Measuring Probe Calibration. Manufacturing Technology. 2018, 18(6), 1053-1059. ISSN 12132489. Dostupné z: doi:10.21062/ujep/223.2018/a/12132489/MT/18/6/1053 